\title{
The Critical Need to Build a European Governance Model for Online Access to Medical Information Services: A Position Paper
}

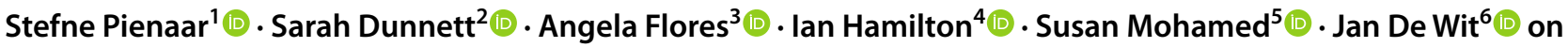 \\ behalf of MILE (Medical Information Leaders in Europe)
}

Accepted: 22 April 2021 / Published online: 14 July 2021

(c) The Author(s) 2021

\begin{abstract}
European pharmaceutical companies have a legal requirement to provide non-promotional Medical Information (MI) services to support healthcare professionals (HCPs) who are using their medicinal products. While the industry has self-regulating bodies with established Codes of Practice, these mainly focus on promotional messaging and commercial activities. In the absence of similar frameworks for MI, such services struggle to understand how to meet HCP digital expectations, often in fear of breaching the promotional codes. This is limiting access to the wealth of non-promotional patient-focussed information held within the industry. Meanwhile, a large volume of unregulated, low-quality information can be readily found on the internet. To understand the current status, the Medical Information Leaders in Europe (MILE) industry association performed a benchmarking survey which explored the online MI service provision of 13 mid-large pharmaceutical companies across Europe. This highlighted a great diversity in approach in terms of geographical coverage and content. Visibility and access for HCPs is complex, compromising online engagement and website utilisation. This MILE position paper highlights the critical need to establish a clear governance model, which empowers pharmaceutical company MI functions to provide unbranded, non-promotional, medicinal product information sources to support HCP online information needs. It is essential to build confidence, transparency and trust by establishing a practical quality framework with principles and standards for online MI services for HCPs.
\end{abstract}

MILE (Medical Information Leaders in Europe) membership listing is published on this webpage https://www.mile-association. org/our-members.

Stefne Pienaar

stefne.pienaar@pfizer.com

Pfizer, Tadworth, UK

2 Sarah Dunnett Consulting Ltd, Newbury, UK

Lilly, Madrid, Spain

4 Lilly, Basingstoke, UK

5 Pfizer, Capelle aan den Ijssel, Netherlands

6 GSK, Wavre, Belgium

\section{Key Points}

Currently, there is no specific framework governing the provision of online medical information by the pharmaceutical industry for healthcare professionals (HCPs) in Europe.

A literature review and benchmarking survey confirmed that there is a gap between the needs of HCPs and the online service offering.

This position paper advocates the collaboration of key stakeholders across Europe to develop and implement a governance model and quality framework to enable company Medical Information (MI) functions to better meet the online medical information needs of HCPs. 


\section{Introduction}

Medical Information (MI) services, similar to contact centres in other industries, have observed an evolution of communication channels. There is still significant use of phone and e-mail, while modern digital channel offerings and uptake are growing slowly. Pharmaceutical companies are expanding the options, providing greater customer choice, e.g., chatbots (virtual assistants) and dedicated self-service websites.

The existing regulations and codes provide great clarity for commercial activities; they are valued by both the industry and HCP community, building trust and supporting professional interactions. By establishing a specific governance model for online MI services across Europe, the pharmaceutical industry would be in the position to develop impactful professional online services for HCPs to better meet patient needs.

MILE (Medical Information Leaders in Europe) is an industry association founded in 2018. It is open to all European pharmaceutical companies that hold marketing authorisations for the use of human medicinal products in the continent of Europe. MILE works to share knowledge and best practice around the function of MI in Europe, with an overall goal to continuously improve access to information about medicinal products for HCPs and patients, and thereby contribute to a safer and more appropriate use of such products. This paper details MILE's position relating to the online provision of MI services, the current challenges and opportunities for the future.

\subsection{Healthcare Professionals and Internet Research}

Anytime-anywhere virtual access to quality information is increasingly commonplace and expected by us all. HCPs too, have a wide range of information needs, adopting different information-seeking behaviours, referring to various sources and sometimes valuing the practicality of unauthoritative sources [1, 2]. Recently, Krenyyukov and Nasy highlighted the developing needs and changing expectations of HCPs for pharmaceutical companies to innovate their digital communication channels, especially regarding clinical evidence (both controlled clinical trials and realworld evidence) and scientific information [3]. A significant number of HCPs also find it helpful to discuss clinical topics on social media; by May 2019, it was estimated that 640,000 HCPs were on Twitter globally [4].

Surveying approximately $200 \mathrm{HCPs}$ in the USA in 2017, Fung et al explored their preferences to access such information [5]. For physicians, journal articles and internet resources were equally favoured $(29 \%$ and $28 \%$, respectively). However, $49 \%$ of non-physicians (nurses, pharmacists, and nurse practitioners/physician assistants) primarily chose internet resources. For both groups, professional websites dominated the internet resources they would use (90-93\%) while prospective studies, guidelines and meta-analyses were considered the most useful for making treatment decisions. Almost half of the HCPs expressed interest in enrolling in a programme to receive updated information relating to their past enquiries with pharmaceutical companies.

A 2019 survey of 700 EU-5 (Germany, Spain, France, UK and Italy) physicians reported their daily use of online professional information sources [6]. Search engines were most prevalent $(68 \%)$ while non-pharma resources were quite popular, for example $23 \%$ used medical websites and $13 \%$ used government websites. The current range of pharmaceutical company resources was referred to less frequently (for example 10\% used company websites and 8\% used product websites). Only $32 \%$ considered that company websites influenced clinical decisions, in comparison to $62 \%$ for search engines and $70 \%$ for professional society websites. While the current range of pharmaceutical company websites are clearly not currently meeting the physician needs, there is great potential for the non-commercial functions of industry, such as MI operations, to provide better access to their expert, unbranded knowledge through dedicated websites.

While many HCPs use professional literature searching tools to identify published journal articles, it can consume significant time for them to collate a useful summary and some essential emerging information and product details are not published.

The high volume of health- and medicine-related misinformation and poorly maintained information on the internet is a major concern $[7,8]$. It is recognised that there is extensive low-quality information regarding medicines on social media [9] and even in online medicine compendia that would be referred to by HCPs [10]. As this may be harmful to public health, the Food and Drug Administration (FDA) has published draft guidance to enable US pharmaceutical companies to ethically voluntarily correct issues identified on independent third-party platforms [11]. However, to support HCPs clinical decision-making world-wide, accurate and up-to-date medicines information needs to be easy to find. Use of medicines outside of their license is sometimes included in published clinical trials, real-world evidence and therapy guidelines, but this is not always clear to HCP readers [12]. As patient treatments become more complex and personalised, fast and efficient access to trusted, legitimate information is all the more important.

COVID-19 presented HCPs with additional challenges and has been associated with a massive 'infodemic' - an overabundance of information-some accurate, some 
not - that makes it hard to find trustworthy sources and reliable guidance when needed [13]. In parallel, there have been many questions and concerns regarding the future supply of critical and long-term medication, the impact on ongoing clinical studies, compassionate-use access, ongoing COVID19 studies, as well as fake news around miracle medicine cures. Reacting one-by-one to questions is neither transparent nor efficient. However, the online provision of legitimate information could well have helped overcome much misinformation and ensured patient-centric, efficient, professional support for frontline HCPs.

\subsection{Regulatory Framework Affecting Medical Information}

The long-standing European Directive 2001/83/EC relating to the regulation of medicinal products for human use mandates pharmaceutical companies to provide a professional scientific service to support the appropriate use of medicines for patients (within Article 98, and notes 40 and 529). However, the methods and channels used to deliver this MI service are not defined and this results in a great diversity in approach. Non-promotional responses to specific questions are defined as being out of scope of the advertising regulations (Article 86).

Restrictions relating to the provision of information for patients also significantly impacts how the industry can provide information to HCPs online. Article 88 of the European Directive 2001/83/EC prohibits the advertising of prescription-only medicines to the general public (except vaccination campaigns) and there is no clarity regarding the provision of medical information to the public within the related Regulation (EC) No 726/2004. In 2008, following extensive consultation and impact assessments, the European Commission published proposals to advance the provision of 'Information for Patients' by pharmaceutical companies, including the online channel. ${ }^{1}$ However, these have not been adopted or implemented.

Both the International Federation of Pharmaceutical Manufacturers and Associations (IFPMA) and the European Federation of Pharmaceutical Industries and Associations (EFPIA) provide strong leadership across the industry to advance patient care through representation and collaboration with healthcare-related organisations and regulatory bodies, and policy development. Both publish Codes of

\footnotetext{
1 Proposals for amendments to the Regulation (EC) No 726/2004 and Directive 2001/83/EC were published in 2008 regarding information to the general public on medicinal products subject to medical prescription. $\operatorname{COM}(2008) 662$ concerned the Regulation (https://eur-lex. europa.eu/legal-content/EN/TXT/?uri=CELEX:52008PC0662), and $\operatorname{COM}(2008) 663$ (https://eur-lex.europa.eu/legal-content/EN/TXT/? uri=CELEX:52008PC0663) concerned the Directive.
}

Practice covering the promotion of medicines and interactions with HCPs, medical institutions, patients and patient organisations $[14,15]$. While they provide an established and progressive self-governing model for the ethical implementation of the European Directive and Regulation, there is very limited mention of non-commercial services like MI.

Currently, there is little specific guidance at an international or regional level regarding the digital communication channels, so non-digital principles prevail. Regulatory bodies in some countries accept that, so long as a pharmaceutical company publishes adequate non-promotional patient-directed content on their website, promotional material clearly intended for HCPs may be open-access without password controls (for example, Medicines and Healthcare products Regulatory Agency Blue Guide [16]). However, there is still no provision for non-promotional information for HCPs online.

The absence of specific criteria regarding the practical provision of medical information in the Directive, Regulation or Codes mentioned above effectively limits the industry from providing comprehensive and constructive non-promotional services for HCPs online-companies are fearful of being inappropriately perceived as promotional.

The European Medicines Agency review 'EMA Regulatory Science to 2025' was published in January 2020. This summarised their vision and five strategic goals relating to the governance and advancement of human medicines for patients [17]. It called for greater innovation and collaboration, in part, to improve clinical decision making and enhance patient care. There is clear recognition of the growing demand for transparency and information for HCPs and there are many areas where online MI services could complement and contribute to the digital transformation. For example, as the EMA strives to deliver improved electronic product information (ePI) - to facilitate access to relevant expertise and knowledge, and to improve communication for patients, HCPs, payers and other stakeholders-MI functions should become a trusted accessible channel for pharmaceutical industry medicine knowledge.

\subsection{Quality Standards for Medical Information}

Some European countries have well established collaborative multi-company associations, which publish guidelines relating to MI services-examples are listed below:

- Germany: Die Forschenden Pharma-Unternehem (VfA), the German Association of Research-Based Pharmaceutical Companies 'Positionspapier-Medizinische Information durch die forschenden Pharma-Unternehmen in Deutschland', 2020 [18]

- Spain: Associación de Medicina de la Industria Farmacéutica Medical Information Forum 'Good Medical 


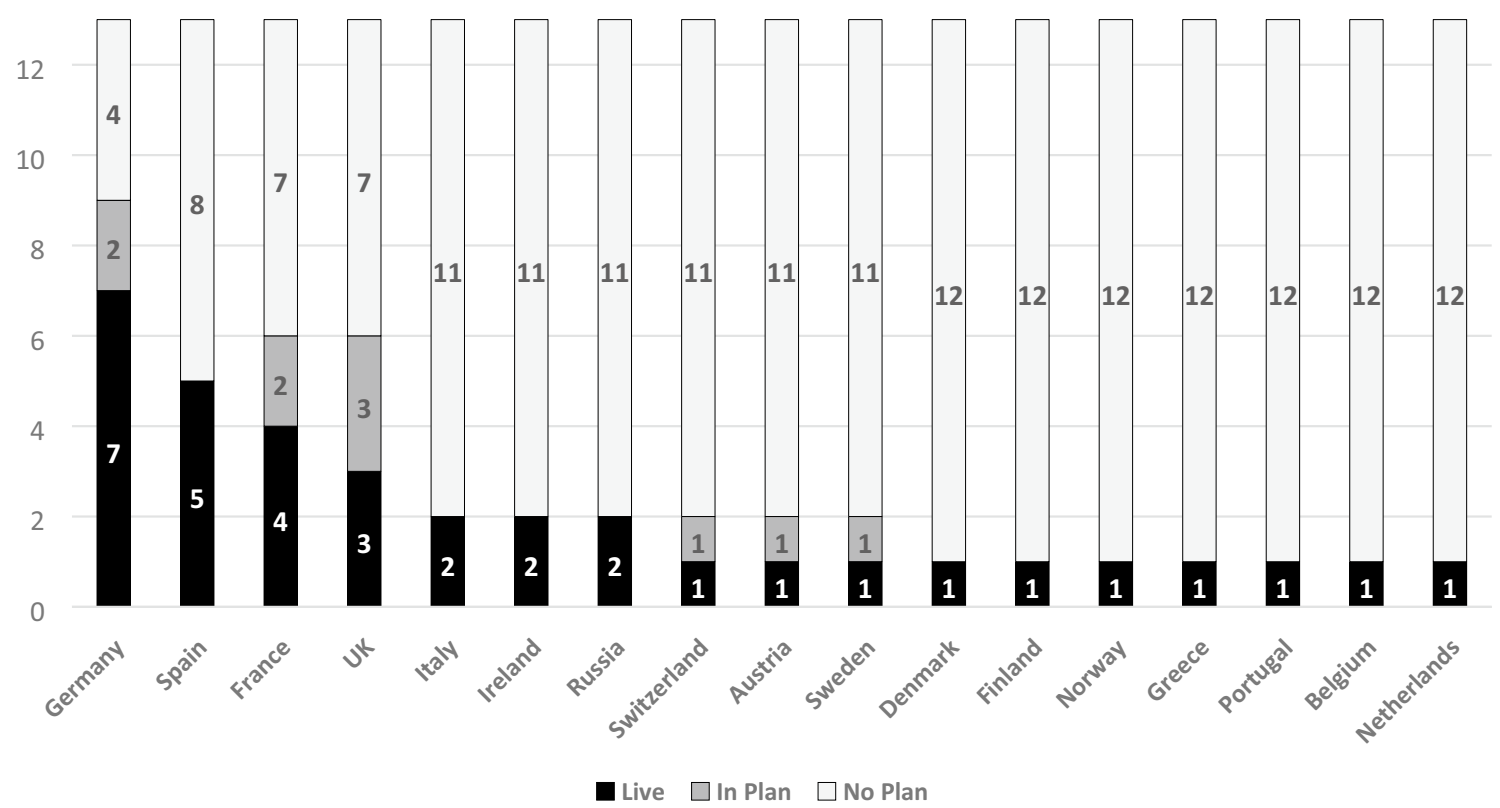

Fig. 1 Number of companies that had a dedicated Medical Information website or were planning to launch a Medical Information website across 17 European countries (September 2019)

Information Practice Guidelines in the Spanish Pharmaceutical Industry', 2017 [19]

- UK: Pharmaceutical Information and Pharmacovigilance Association 'UK Guidelines for the Pharmaceutical Industry Medical Information Departments’, 2019 [20]

These guidelines typically cross-reference to the European and national legislative and promotional compliance codes, guiding that services must provide reactive, non-promotional, unbranded, accurate, fair, balanced and objective answers to HCP questions to facilitate the safe and effective use of the medicines for patients. However, they do not address online provision of MI services.

\section{Benchmarking Survey of Pharmaceutical Company Medical Information Websites}

In 2019, 13 of the 20 MILE member companies responded to a 32-question survey relating to the adoption of digital technologies and solutions across the industry. An Excel spreadsheet with fixed dropdown options was used to collect the responses. The scope included the 17 largest countries in the geography of Europe (including Russia, but excluding Turkey, as most pharmaceutical companies consider this as part of Asia or their Middle East regions). Information collected focussed on enquiry volumes received by MI functions in 2018 and company-owned dedicated MI websites in 2019. The data were processed externally, and the anonymised results were presented to MILE members. The following key observations were made and endorsed by the MILE membership as reflecting the status of the digital provision of MI services in Europe.

\subsection{Low Website Utilisation Despite High Enquiry Volumes}

The 13 participating companies indicated that approximately 770,000 customer enquiries were received and managed from the 17 European countries in scope. Approximately $80 \%$ of enquiries originated from HCPs and $20 \%$ from consumers. Extrapolating this to the full pharmaceutical landscape would indicate that multiple millions of enquiries are received annually, clearly demonstrating the significant information needs that are met by company MI functions. Companies indicated low utilisation of MI websites with less than $6 \%$ answered through online channels.

\subsection{Limited Coverage by Dedicated Online Medical Information Websites}

Companies were asked whether they had a MI website for HCPs and indicated whether they currently had a live website, were planning to launch a website or had no plans to do so (Fig. 1). The response showed a large degree of variance in the availability of dedicated MI websites across countries. Germany was shown to have the highest availability, followed by Spain, France and the UK. Only one company indicated having MI websites live in all countries included in the survey. 


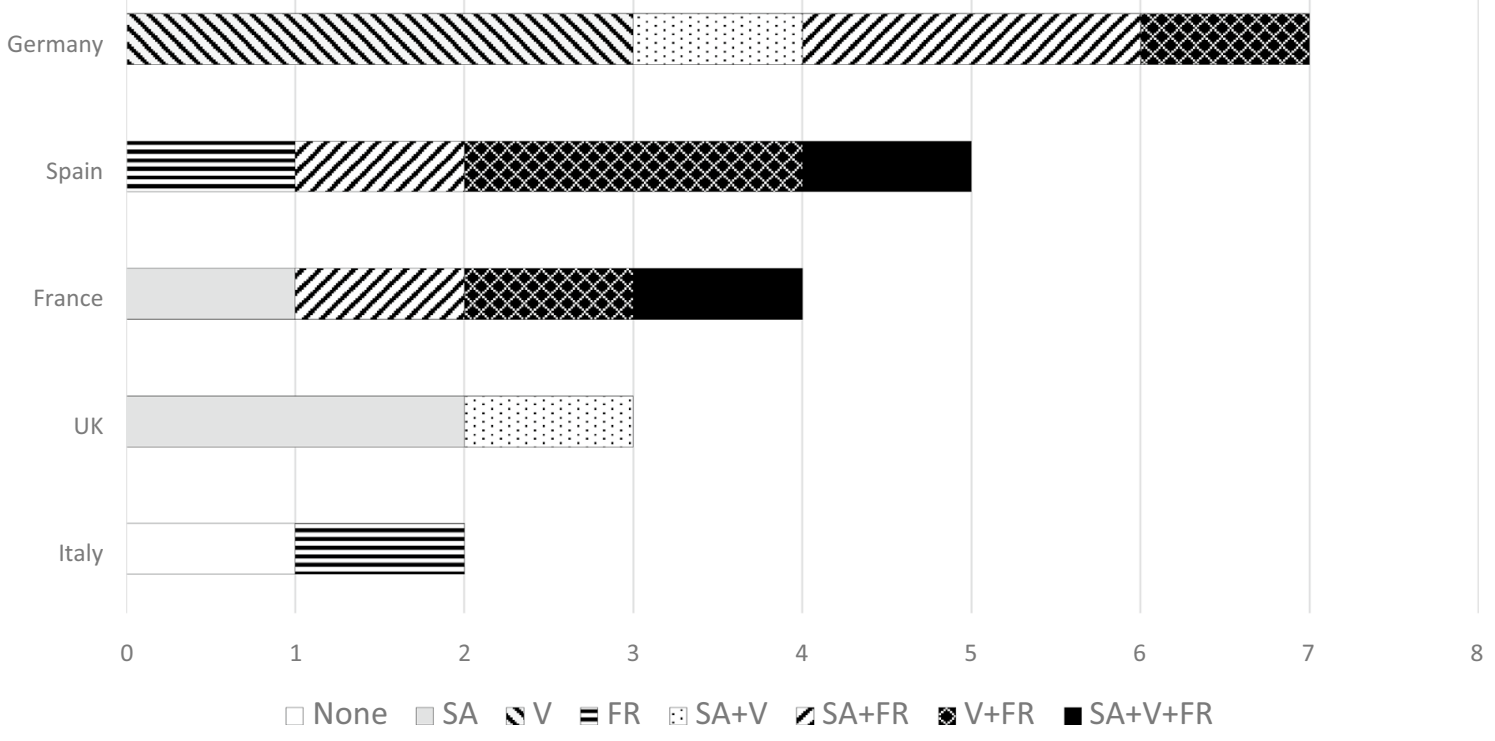

Fig. 2 Healthcare professional (HCP) verification methods in place across EU-5 websites (September 2019). None = Open access; $F R$ full registration (HCP creates an individual account); $S A$ self-authen-

Due to the low presence of MI websites in most countries, the subsequent analysis of the survey in this paper will focus on the EU-5 countries.

\subsection{Variance in HCP Verification Methods Deployed Across Companies and Countries in the EU-5}

Companies were asked to confirm which HCP verification methods, if any, were deployed on their live websites, selecting one or more of four predefined options: Self-Authentication, Validation, Full Registration or None.

Figure 2 summarises how a range of HCP verification methods are used across such websites. There was great diversity in approach between companies and across countries. For example, for full access to all content, the Spanish websites required full registration, while in the UK (except for one company) users were granted full access through self-certification. In Germany, verification approaches varied, including validation, self-authentication with validation and/or full registration with validation. Twelve of the websites employed more than one method, with stricter verification required to access certain content.

\subsection{Mixed Website Content in the EU-5}

Companies were also asked if the content and services available on their websites included: enquiry submission, MI contact details; links to Summary of Product Characteristics (SmPC); searchable scientific responses - and whether on-label or outside of label; a customer satisfaction survey; a tication (HCP simply clicks, confirming their HCP status); $V$ validation (HCP submits name, role and professional registration number for checking)

live chat function; list of FAQs (frequently asked questions) or video chat (Fig. 3).

Most websites offered core functionalities such as enquiry submission, contact details and links to SmPCs. However, additional content and services were less frequently offered, e.g. chat live functionalities, searchable scientific responses including information outside of the label and/or a list of FAQs. Even for websites requiring a full registration, companies did not always provide online access to their full scientific responses. In addition, a German-based HCP more frequently has access to searchable scientific responses that include information outside the label compared with HCPs based in Spain, France, the UK or Italy.

\subsection{Benchmarking Survey Conclusions}

The findings from the survey highlight the variance in, and limited provision of, online medical information by pharmaceutical companies across European countries. Germany was the most widely supported with $54 \%$ of companies surveyed having a website available. However, in most of the countries surveyed there was only a single company providing a MI website. In comparison, a 2018 USA survey co-ordinated by phactMI (Pharma Collaboration for Transparent Medical Information), found that $74 \%$ (20/27) of companies offered online MI services [21].

There is a large degree of variance in HCP verification methods utilised within countries and across companies. The low number of sites using self-authentication is striking in comparison to the USA where phactMI found that, in 2018, 


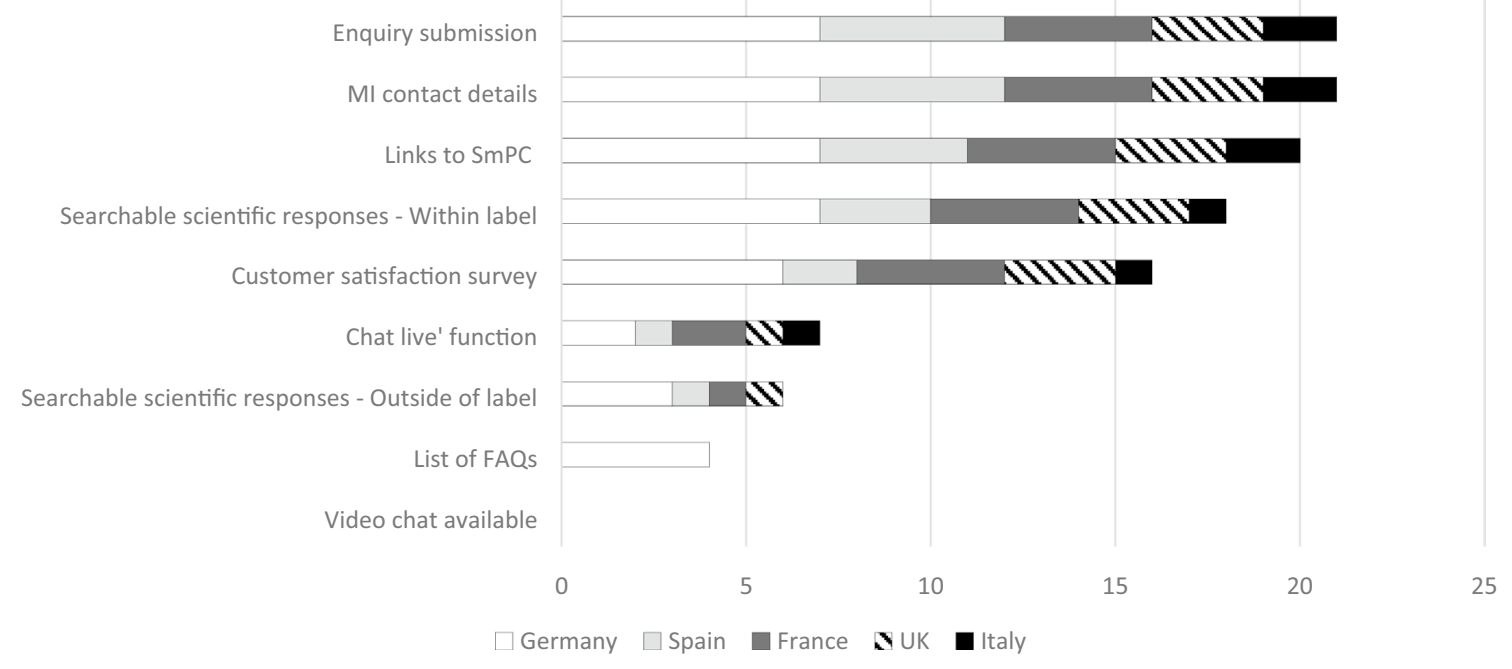

Fig. 3 Availability of different content and tools across 21 EU-5 websites (September 2019). FAQs frequently asked questions; SmPC summary of product characteristics

11 of 20 MI websites used self-authentication, with 2 of the sites requiring no verification at all [21]. It is also important to recognise that traditional phone and email MI services apply HCP self-authentication only. Stricter online verification methods limit discoverability of content through search engines - recognised as a popular method used by HCPs [5, $6]$. The diverse approaches to verification complicate the HCP experience, creating barriers and delays in accessing information. Such accessibility barriers compromise the value MI functions could bring to clinical decision-making and may drive HCPs to sources that are of lower quality.

Overall, the survey confirmed significant variance between companies and countries with inequality of provision and access barriers potentially preventing HCPs from accessing these otherwise reliable, accurate, evidence-based sources of information.

\section{Proposal}

Medical Information (MI) services across the pharmaceutical industry clearly need to be able to evolve to meet the current and future unmet needs of HCPs. Non-commercial MI services already efficiently and professionally respond to a wide range of on-label and outside of license enquiries from HCPs [22]. It should therefore be possible for companies to adopt the same practical approach, allowing services to be replicated online consistently across the region. We therefore recommend the development of a specific governance model to enable high-quality content to be published and maintained by pharmaceutical companies online to support HCPs as they care for patients.

\subsection{Governance Model and Quality Framework for Online Medical Information}

Within Europe, the International Conference on Harmonisation consensus guideline, ICH E6 (R2), is well established to ensure good clinical practice of studies [23] and a quality framework has been developed to facilitate industry-provided medical education [24]. Learning from these related disciplines, we propose the development and adoption of a new governance model and quality framework for online MI.

This could be established as a stand-alone framework, or as an annex to existing EMA or EFPIA publications. We also recommend engaging with the national multi-company MI associations to facilitate the implementation of the framework.

To initiate discussions, we have drafted a quality framework, which includes twelve standards across three core principles-as shown in Fig. 4.

The implementation of this proposal, and improved visibility of professional information by HCPs, might be facilitated by pharmaceutical companies listing their products and MI service details within a common platform-for example, the European Medical Information Gateway as developed and described by the MILE association (https://www.migat eway.eu) [25].

\section{Conclusions}

Despite the clear need, pharmaceutical company Medical Information (MI) services across Europe continue to be constrained from providing essential online resources for HCPs due to the application of promotional codes to this 


\begin{tabular}{|c|c|c|}
\hline Ethical, professional, trusted resource & Non-commercial intent, for HCPs only & Integrated, accessible service \\
\hline - Include needs-based content and & - Maintain a dedicated non- & - Provide Medical Information service \\
\hline coverage considering the product & commercial website. & contact details and/or portal for \\
\hline range, topics and geographies & - Ensure the intended audience is & enquiry submission and feedback. \\
\hline supported. & clearly defined on the website and & - Include clear guidance and a \\
\hline - Provide balanced, objective, & content. & practical process to submit drug \\
\hline referenced, up-to-date content in a & - Include a clear statement where the & safety and product quality concerns. \\
\hline suitable format (e.g. FAQs, product & information is not for patients or & - Ensure continuous access and \\
\hline profiles, clinical summaries, & members of the public. & integrity of all links. \\
\hline literature overviews). & - Provide access through HCP self- & \\
\hline - Include search functionality to & authentication - where a HCP is & \\
\hline facilitate access to all relevant & defined as an individual caring for & \\
\hline information about the medicines and & patients or involved in healthcare & \\
\hline their use. & policy with a legitimate professional & \\
\hline - Maintain high quality through & need for the information. & \\
\hline quality monitoring, scheduled & - Exclude any product branding or & \\
\hline reviews and clearly documented & disguised promotion - judicious use & \\
\hline revision dates. & of the brand name only to enable & \\
\hline & initial retrieval of relevant & \\
\hline & information. & \\
\hline
\end{tabular}

Fig. 4 Provisional quality framework for online medical information provision in Europe

non-commercial activity. In the absence of a MI framework, fear of breaching promotional codes is stifling development, consuming valuable HCP time and compromising patient care.

Although mandated to provide MI services, this is constrained to twentieth century channels with limited scope to evolve to meet the developing needs of HCPs. While the industry has collated highly valuable experience and knowledge regarding the products they have researched, developed, manufactured and supply, this is less accessible to HCPs than unregulated, low-quality web content.

Collectively, the pharmaceutical industry, regulators and industry associations have a social and professional responsibility to urgently develop and implement a specific governance model and quality framework for online MI resources. This is required to enable companies to deliver online resources for HCPs that will better support their practice of evidence-based medicine and healthcare decision making.
The MILE association welcomes all stakeholders to engage with this proposal and help refine and implement this essential governance model.

Acknowledgements The authors would like to thank Katie Gibson, Janssen Pharmaceutica NV, for her valuable review of the manuscript. The views expressed in this publication are those of the MILE (Medical Information Leaders in Europe) association and are not necessarily the views of each of the author's companies or other MILE member companies. MILE can be contacted via info@mile-association.org.

\section{Declarations}

Funding MILE (Medical Information Leaders in Europe) covered the costs associated with publication of this article, including engaging research and author services from Sarah Dunnett. No other financial support was received.

Conflicts of Interest/Competing interest MILE is an industry association that works to share knowledge and best practice around the 
function of Medical Information in Europe, with an overall goal to continuously improve access to information about medicinal products for healthcare providers and patients. Stefne Pienaar is an employee and shareholder of Pfizer, Sarah Dunnett is Director and shareholder of Sarah Dunnett Consulting Limited and shareholder of Baxter and Takeda, Angela Flores in an employee and shareholder of Lilly, Ian Hamilton was an employee of Lilly while this activity was undertaken and is now Director and shareholder of Original Digital Limited, Susan Mohamed is an employee of Pfizer, Jan De Wit was an employee and shareholder of GSK while this activity was undertaken.

Ethics approval Not applicable.

Consent to participate Not applicable.

Consent for publication Not applicable.

Availability of data and material From Corresponding Author on reasonable request.

Code availability Not applicable.

Author contributions All authors were involved in researching, authoring and reviewing the manuscript. Ian Hamilton and Susan Mohamed were also involved in designing and analysing the benchmarking survey. All authors have read and approved the final manuscript.

Open Access This article is licensed under a Creative Commons Attribution-NonCommercial 4.0 International License, which permits any non-commercial use, sharing, adaptation, distribution and reproduction in any medium or format, as long as you give appropriate credit to the original author(s) and the source, provide a link to the Creative Commons licence, and indicate if changes were made. The images or other third party material in this article are included in the article's Creative Commons licence, unless indicated otherwise in a credit line to the material. If material is not included in the article's Creative Commons licence and your intended use is not permitted by statutory regulation or exceeds the permitted use, you will need to obtain permission directly from the copyright holder. To view a copy of this licence, visit http://creativecommons.org/licenses/by-nc/4.0/.

\section{References}

1. Demergazzi S, Pastore L, Bassani G, Arosio M, Lonati C. Information needs and information-seeking behavior of Italian neurologists: exploratory mixed methods study. J Med Internet Res. 2020;22(4):e14979.

2. Mikalef P, Kourouthanassis PE, Pateli AG. Online information search behaviour of physicians. Health Info Libr J. 2017;34(1):58-73.

3. Krendyukov A, Nasy D. Evolving communication with healthcare professionals in the pharmaceutical space: current trends and future perspectives. Pharm Med. 2020;34:247-56.

4. Creation. More healthcare professionals are on Twitter than ever before. 2019. https://creation.co/knowledge/more-healthcare-profe ssionals-are-on-twitter-than-ever-before/. Accessed 16 Apr 2021.

5. Fung SM, Sud C, Suchodolski M. Survey of customers requesting medical information: preferences and information needs of patients and health care professionals to support treatment decisions. Ther Innov Regul Sci. 2020;54(1):75-84. https://doi.org/10.1007/ s43441-019-00031-3.

6. Decision Resources Group Manhattan Research, Taking the Pulse Europe 2019 - Device use and information sources. 2019. https://decisionresourcesgroup.com/report/ttpxeu0027-digit al-taking-the-pulse-europe-2019/. Used with permission. Accessed 16 Apr 2021.

7. Swire-Thompson B, Lazer D. Public health and online misinformation: challenges and recommendations. Annu Rev Public Health. 2020;41:433-51.

8. Wang Y, McKee M, Torbica A, Stuckler D. Systematic literature review on the spread of health-related misinformation on social media. Soc Sci Med. 2019;240:112552. https://doi.org/10.1016/j. socscimed.2019.112552.

9. Khaja KAJ, AKhaja AK, Sequeira RO. Drug information, misinformation, and disinformation on social media; a content analysis study. J Public Health Pol. 2018;39:343-57. https://doi.org/10.1057/ s41271-018-0131-2.

10. Talwar SR, Crudele NT, Dankiewicz EH, Randhawa AS, Haddox JD. Implementing a process to review product-specific misinformation in online drug information compendia. Therap Innov Regul Sci. 2015;49(2):262-8.

11. U.S. Department of Health and Human Services Food and Drug Administration. Guidance for Industry-Internet/social media platforms: correcting independent third-party misinformation about prescription drugs and medical devices. 2014. https://www.fda.gov/ media/88545/download. Accessed 16 Apr 2021.

12. European Union. Study on off-label use of medicinal products in the European Union. 2017. https://ec.europa.eu/health/sites/health/ files/files/documents/2017_02_28_final_study_report_on_off-label_ use_.pdf. Accessed 16 Apr 2021.

13. Pan American Health Organisation and World Health Organisation. Understanding the infodemic and misinformation in the fight against COVID-19. Factsheet 5. 2020. https://iris.paho.org/bitstream/handle/10665.2/52052/Factsheet-infodemic_eng.pdf?sequence $=14$. Accessed 16 Apr 2021.

14. International Federation of Pharmaceutical Manufacturers and Associations. Code of Practice. 2019. https://www.ifpma.org/wp-content/ uploads/2018/09/IFPMA_Code_of_Practice_2019-1.pdf. Accessed 16 Apr 2021.

15. European Federation of Pharmaceutical Industries and Associations. Code of Practice. 2019. https://www.efpia.eu/media/554677/efpia_ codes_a5_v3-2021_sm.pdf. Accessed 16 Apr 2021.

16. Medicines and Healthcare Products Regulatory Agency. Blue Guide November 2020. 3rd Edition-3rd revision, section 6.3. https:// assets.publishing.service.gov.uk/government/uploads/system/uploa ds/attachment_data/file/956846/BG_2020_Brexit_Final_version. pdf. Accessed 16 Apr 2021.

17. European Medicines Agency. EMA Regulatory Science to 2020Strategic reflection. 2020. https://www.ema.europa.eu/en/docum ents/regulatory-procedural-guideline/ema-regulatory-science-2025strategic-reflection_en.pdf. Accessed 16 Apr 2021.

18. Die Forschenden Pharma-Unternehem (VfA), the German Association of Research-Based Pharmaceutical Companies. 'Positionspapier-Medizinische Information durch die forschenden PharmaUnternehmen in Deutschland', 2020. https://www.vfa.de/download/ positionspapier-medizinische-information.pdf. Accessed $16 \mathrm{Apr}$ 2021.

19. Associación de Medicina de la Industria Farmacéutica Medical Information Forum. 'Good Medical Information Practice Guidelines in the Spanish Pharmaceutical Industry', 2017. https://www.docum entauniversitaria.com/en/products/gua-de-buenas-prcticas-de-infor macin-mdica-en-la-industria-farmacutica-espaola/. Accessed $16 \mathrm{Apr}$ 2021.

20. Pharmaceutical Information and Pharmacovigilance Association. 'UK Guidelines for the Pharmaceutical Industry Medical Information Departments', 2019. https://pipaonline.org/wp-content/uploa ds/2020/05/UK-Guidelines-for-the-Pharmaceutical-Industry-Medic al-Information-Departments-Revised-2019.pdf. Accessed $16 \mathrm{Apr}$ 2021. 
21. Patel P, Gaspo R, Crisan A, Lee J. Where are we now in providing medical information in the digital space? A benchmark survey of phactMI Member Companies. Therap Innov Regul Sci. 2020;54(6):1282-90.

22. Hristoskova S, Milligan J, De Wit J, Pesonen J, Rennick R. Principles and considerations for responsible sharing of safety information via the medical information channel. Therap Innov Regul Sci. 2020;54(4):939-46. https://doi.org/10.1177/2168479019872141.

23. European Medicines Agency. ICH E6 (R2) Good Clinical Practice. 2016. https://www.ema.europa.eu/en/ich-e6-r2-good-clinical-pract ice. Accessed 16 Apr 2021.
24. Allen T, Donde N, Hofstadter-Thalmann E, Keijser S, Moy V, Murama JJ, Kellner T. Framework for industry engagement and quality principles for industry-provided medical education in Europe. J Eur CME. 2017. https://doi.org/10.1080/21614083.2017. 1348876.

25. Rennick R, Barrias A, Davies J, De Wit J, Eggert S, Flores A, Gibson K, Hamilton I. To surf or not to surf? Accessing reliable, accurate medical information. J Gen Pract. 2019;7:374. 